\title{
LA ACUSACIÓN FISCAL Y LA AUDIENCIA PRELIMINAR
}

\author{
Gino M. Valdivia Sorrentino*
}

\begin{abstract}
Resumen
Con la inserción del nuevo modelo acusatorio en la legislación procesal penal, el Ministerio Público sigue siendo el facultado para ejercer la función acusatoria, y en merito a ella tomar decisiones que determinarán el desarrollo del proceso. Figuras jurídicas como las Convenciones Probatorias han sido incluidas para celebrar acuerdos con el imputado y prescindir de la actividad probatoria, lo que contribuirá a la celeridad del proceso y disminución de la carga procesal. Es así que bajo las disposiciones del Nuevo Código Procesal Penal deberá realizarse una acción coordinada entre el Ministerio Público y el Poder Judicial bajo el prisma de los principios de congruencia y participación procesal.
\end{abstract}

Palabras clave: Investigación preparatoria - Nuevo Código Procesal Penal principio de congruencia probatoria.

\begin{abstract}
With the insertion of the new accusatory model in the penal procedural legislation, the State Attorney's General Office continues being the authorized one to exert the accusatory function and in merit to it to make decisions that will determine the development of the process. Legal figures as the Probatory Conventions have been including to sign agreements with the imputed and eliminate the probatory activity, which will contribute to the speed of the process and the diminution of the number of cases. This way, and under the disposition of the New Criminal Procedural Code the actions must being realized in coordination between the State Attorney's General Office and the Judicial Power under the principles of the congruence and the procedural participation.
\end{abstract}

Key words: Preliminary investigation - New Crocedural Criminal Code principle of probatory congruence.

\section{Sumario}

1. Introd ucción. 2. Las convenciones probatorias. 3. Desarrollo de la audiencia preliminar o de control. 4. Trascendencia de la acusación alternativa o subsidiaria en la audiencia preliminar.

* Juez Especializado Titular de la Corte Superior de Justicia de Arequipa - Poder Judicial de Perú. 


\section{INTRODUCCIÓN}

Dentro de las novísimas disposiciones contenidas en nuestro Código Procesal Penal - Decreto Legislativo $N^{\circ} 957$, tenemos aquella que prevé que una vez concluida la etapa de investigación preparatoria regulada en el artículo $334^{\circ}$ y siguientes, sobreviene como facultad del Ministerio Público - en ejercicio de su función acusatoria -, pronunciarse en referencia, bien por la formulación de acusación o caso contrario, por el sobreseimiento del proceso (Artículo $\left.344^{\circ} .1\right)$.

Esta opción legal, mantenida como prerrogativa funcional desde la otrora normativa contenida en el Código de Procedimientos Penales, recae fundamental y únicamente en la persona del fiscal como titular de la acción penal pública, aptitud legal que se encuentra contenida en el artículo $11^{\circ}$ de la Ley Orgánica del Ministerio Público (D. Legislativo $\mathrm{N}^{\circ}$ 052) y comprende su capacidad de decisión, para lo cual debe valorar tanto la actividad probatoria (elementos de convicción) desplegada y obtenida tanto en el decurso de la etapa de la investigación preliminar, cuanto en la de investigación preparatoria y que el Código Procesal Penal denomina como "base suficiente".

De este modo, a la culminación de la etapa de investigación preparatoria, el Ministerio Público se halla en aptitud legal de accionar, bien hacia la fase de juzgamiento, o en su defecto, a la de sobreseimiento del proceso; todo ello a través de la formulación de acusación o pedido de archivo, respectivamente. (Artículo $343^{\circ}$, último párrafo).

En el tema que nos ocupa, analizaremos la primera de las opciones; esto es, la formulación de acusación fiscal (Artículo $349^{\circ}$ ), la misma que según la novísima legislación, resulta susceptible de ser sometida a análisis previo, en referencia a su contenido "formal" y además, de pertinencia probatoria, admitiéndose para ello determinados mecanismos de defensa, inclusive hasta en contra de la acción penal.

Consecuentemente, respecto de este primer extremo del aplicativo de una suerte de filtro o tamiz, de modo previo a la decisión de emisión o no del au to de enjuiciamiento, precisamos que nuestra reciente normatividad regula toda esta actividad en la denominada "audiencia preliminar" o "audiencia de control", realizable en la etapa intermedia del proceso penal, constituyendo aquella un estadío procesal único en el cual se despliegan los actos procesales enunciados en el párrafo precedente. 
Expuestos estos hechos iniciales, compete señalar ya en desarrollo del tema, que una vez recibida la acusación fiscal por el juez de la investigación preparatoria, esta es notificada a las partes procesales, quienes tienen 10 días de plazo para ejercitar las facultades que les concede el artículo $350^{\circ}$ del Código Procesal Penal entre las que se hallan: a) observar la acusación por defectos formales; b) interponer medios técnicos de defensa en su contra y hasta excepciones (Artículo $7^{\circ} .2$ ); c) instar un criterio de oportunidad y; d) otras distintas posibilidades de defensa; todo lo cual determina se haya tenido que regular con este fin la denominada "audiencia preliminar", diligencia procesal que se sustenta en los principios de derecho de defensa y participación procesal (Artículo X del Título Preliminar del Código Procesal Penal) referidos tanto para el imputado como para la parte agraviada.

Esta facultad de cuestionar la acusación fiscal - como se tiene dicho -, incumbe únicamente su aspecto formal, mas no de fondo, dado que al ser notificada a las partes procesales, se permite que en el plazo legal de 10 días, no sólo estén impetradas - de modo previo a la celebración de la audiencia preliminar - de todos y cada uno de los aspectos formales y sustantivos que aquella contiene (Artículo $349^{\circ}$ ), sino también conlleva la potestad de formular cuestionamientos, de tal manera que sobrevenida su realización, sólo sean sometidos a debate, aquellos planteamientos o medios de defensa deducidos en forma antelada. Admitir durante la audiencia, el ejercicio de nuevas peticiones, desnaturalizaría dicho acto procesal dado que las partes ya participan en la audiencia con conocimiento total del caso y con su defensa oral orientada a hechos concretos y predeterminados; pretender hacerlo contrariamente a lo reseñado, sería generar caos procesal, amén de afectar seriamente los principios de contradicción y celeridad procesal, apoyándonos para este aserto, en el carácter perentorio del plazo de diez días concedido a las partes, para oponer tales cuestionamientos.

\section{LAS CONVENCIONES PROBATORIAS}

Doctrinariamente, existen definiciones a ellas como la señalada por María Inés Horvitz Lennon, al descifrar a las convenciones probatorias como "acuerdos de los intervinientes sobre hechos no controvertidos del procedimiento que, al ser aprobados por el juez de garantía, dispensan de la carga de probarlos a través de los medios de prueba legal, hechos que luego no podrán ser discutidos durante el debate."1

Aunándose a esta conceptulización, Carolina Cueva Vaccaro nos dice que "las convenciones probatorias, son acuerdos celebrados entre el imputado y 
el fiscal, cuya finalidad exclusiva es la celeridad del proceso, para lo cual se prescinde del desarrollo de la actividad probatoria (en el sentido de aportación de medios probatorios) sobre hechos o circunstancias respecto de los cuales no existe contradicción entre los sujetos mencionados" ${ }^{\prime 2}$. Rescatamos de ambos conceptos, que la prescindencia de medios de prueba, está orientada de modo puntual: 1) a la carencia de su necesidad de aporte y; 2) a hechos en los cuales, está ausente la contradicción por las partes. Completamos esta idea, aclarando que nuestra moderna legislación, hace permisible las convenciones probatorias entre todos los sujetos procesales, a excepción del Fiscal.

Estos acuerdos vienen a constituir el ejercicio de una de las primeras opciones normativas de las que pueden hacer uso las partes procesales (Artículo $350^{\circ} .2$ ) y consisten específicamente en dos facultades estrictamente delimitadas como son: a) el "acuerdo" o "consenso" al que arriban las demás partes procesales (imputado, agraviado, tercero civil, etcétera) respecto de determinados hechos que aquellas dan por acreditados, prescindiéndose de este modo, del aporte de prueba ya innecesaria y; b) el acuerdo de actuación, de necesarios medios de prueba, para que ciertos hechos puedan estimarse probados.

Lo pertinente, será propuesto al Juez de la Investigación Preparatoria, quien podrá - en el primer caso - dar por acreditados los hechos puntualmente convenidos, declarando expresamente que resulta innecesaria la actividad probatoria y su debate en juicio; y - en el segundo - admitir los medios de prueba que las partes han estimado necesarios para la acreditación de ciertos hechos. Sin embargo, la norma permite que el juez podrá desvincularse de la convención probatoria sobre hechos, cuanto estos no incidan en la imputación, punibilidad o responsabilidad civil discutidas en el proceso (Artículo $156^{\circ} .1$ ), aconteciendo lo propio respecto de la propuesta de actuación de medios de prueba que las partes procesales han estimado necesarias, bajo la óptica de no cumplir las exigencias de objeto de prueba que estipula el artículo $157^{\circ} .1$ del Código Procesal Penal.

Esta conducta procesal, complementariamente se ve plasmada en el artículo $156^{\circ} .3$, al permitir el acuerdo de partes de prescindir la probanza de determinada circunstancia, la cual podrá ser valorada por el juez como un hecho notorio.

Doctrinariamente, si bien podría alegarse que esta facultad de admisión de convenciones probatorias se contrapone al principio de necesidad de la prueba, emergen a favor de esta postura legal, su eficacia para la economía procesal y judicial, al permitir ganar tiempo, esfuerzo y costos, amén de 
depurar el juicio de innecesarios debates sobre hechos en los cuales no hay controversia. En esta actividad probatoria inter - partes que promociona el Nuevo Código Procesal Penal, acorde a su modelo acusatorio de inclinación ad versarial, son estas mismas las que dinamizan su desarrollo a partir de este principio de proposición o convención probatoria, que de obtener amparo, exige auto debidamente fundamentado del juez. Lo propio, cuando el órgano jurisdiccional decide desvincularse de tales acuerdos, siéndole únicamente exigible, justifique fundada y razonadamente, los motivos por los cuales adopta esta decisión de rechazo (Artículo $350^{\circ} .2$ ), dado que su inobservancia, dejaría inválido o carente de efecto legal, este pronunciamiento desestimatorio.

Es indispensable destacar, que el juez de la investigación preparatoria, en esta etapa intermedia en que desarrolla el control de acusación, debe tener conocimiento cabal de todo aquello que acepte como convención probatoria, dado que en este acuerdo previo, bien pueden comprenderse hechos no susceptibles de ser objeto de prueba (Artículo $156^{\circ} .2$ ); que estos no sean pertinentes, conducentes ni útiles (Artículo $352^{\circ} .5$ inc. b) e inclusive, en el caso de estipularse el acuerdo de actuación de medios de prueba, ello no implique vulneración de derechos fundamentales de la persona (Artículo $159^{\circ} .1$ ), esta facultad del juez no informa derecho a valorar la prueba en sí, sino únicamente cautelar su legitimidad verificando ausencia de vulneración a derechos fundamentales.

Destacamos, que la segunda de las opciones legales, de proponer acuerdos para que determinados hechos se estimen como probados, ésta es atinente de modo exclusivo a "los medios de prueba" y no a objeto ni fuente de prueba, las cuales difieren sustancialmente de los primeros. Bajo esta óptica, conceptuaremos que medio de prueba, según Jauchen, "es el método por el cual el juez obtiene el conocimiento del objeto de prueba." ${ }^{3}$

A su turno Villavicencio Terreros nos cita "el medio de prueba es el modo $o$ acto como se adquiere, en el proceso, el conocimiento de un objeto de prueba. Peritajes, inspecciones oculares, testimonios y los numerosos medios de conocer la verdad material (...)". Con ello, podríamos definir los medios de prueba, como todos aquellos instrumentos o procedimientos de actuación dentro de un proceso, susceptibles de proveer una actividad cognoscitiva al Juez.

Me permito de modo ilustrativo, citar el artículo publicado por el doctor Manuel Miranda Estrampes ${ }^{4}$ que involucra el tema tratado y de cuya lectura apreciamos que en atención a la prueba citada en el artículo $159^{\circ} .1$, nos 
conduce a la teoría de la prueba ilícita, señalando sucintamente que concierne a aquella que ha sido obtenida y/o practicada, con prescindencia del respeto a derechos fundamentales y las debidas garantías procesales; ante esta realidad procesal, nuestro vigente ordenamiento procesal penal está diseñado para excluirlas (Artículos II.1 y VIII del Título Preliminar).

\section{DESARROLLO DE LA AUDIENCIA PRELIMINAR O DE CONTROL}

El Código señala que para su instalación, sólo la presencia del Ministerio Público y del defensor del imputado, son obligatorias $\left(351^{\circ} .1\right)$, estando dirigida por el juez de la investigación preparatoria $\left(351^{\circ} .2\right)$, otorgándose el derecho de argumentar oralmente a todas las partes procesales asistentes según orden establecido $\left(351^{\circ} .3\right)$, pudiendo generarse un debate legal sobre las cuestiones planteadas. Es aquí justamente donde el juez realizará la calificación descrita en el apartado anterior, adoptando las probables decisiones ya mentadas, que pueden ser de acreditación o rechazo de las convenciones probatorias y de procedencia o no, de medios de prueba necesarios para estimar como probados determinados hechos.

Si bien, en este último caso y como se tiene dicho, los medios de prueba no constituyen sino un conjunto de actividades que se realizan en el proceso penal con el objeto de proveerlo de prueba sobre los hechos, debe entenderse que aquellos están circunscritos al criterio de medio libre y no de medio legal, puesto que el segundo constrine a las partes a solo emplear los que expresamente prescribe el código respectivo; empero, nuestra normativa $\left(157^{\circ} .1\right)$, otorga libertad de utilizar cualquier otro medio probatorio no comprendido normativamente, excepcionalidad condicionada a la no vulneración de derechos y garantías de la persona y a que su incorporación revista razonable adecuación al medio de prueba más análogo de todos los regulados. Se reafirma que la finalidad de esta audiencia, es permitir modificar, aclarar o integrar la acusación en lo que no sea sustancial, teniendo potestad el juez de la investigación preparatoria, de emitir resolución de sobreseimiento del proceso $\left(351^{\circ} .4\right)$, caso de advertir concurrencia de las causales previstas en el artículo $344^{\circ} .2$.

\section{TRASCENDENCIA DE LA ACUSACIÓN ALTERNATIVA O SUBSIDIARIA EN LA AUDIENCIA PRELIMINAR}

Resulta de vital importancia, determinar que relevancia tendría la facultad concedida al Ministerio Público (Artículo 349 .3 ) de ejercitar su derecho 
acusatorio de modo alternativo o subsidiario, sin afectar el principio de congruencia procesal.

Clariá Olmedo, señala que "la regla de congruencia o de relación, con su significado estricto dentro del proceso penal sólo hace referencia a lo fáctico, mostrándose como una indispensabilidad de coincidencia o conveniencia entre el supuesto de hecho imputado y el contenido fáctico de la decisión, ya que en el aspecto jurídico rige en plenitud el principio iura novit curia." ${ }^{5}$

En este mismo sentido se pronuncia Vélez Mariconde, al afirmar que "la facultad de dar al hecho una calificación jurídica distinta no representa una violación del derecho de defensa."6.

Finalmente, citando a Creus, aquel sostiene que "el principio de congruencia refiere a los 'hechos' no a su calificación jurídica."

Sobre este importante aspecto, analizaremos en primer orden, que la normatividad adjetiva anterior, no regulaba la posibilidad de la denominada "desvinculación procesal", siendo su primer condicionante, una ejecutoria suprema de fines de 1997 emanada por la Sala Penal Permanente, por la cual se asumía el denominado "Principio de Determinación Alternativa" que establecía cuatro presupuestos sustanciales para su aplicación, como son la homogeneidad del bien jurídico tutelado, inmutabilidad de los hechos y pruebas, preservación del derecho de defensa y coherencia de los elementos fácticos y normativos, generándose de este modo - tal como acertadamente lo señala Alfredo Alarcón Flores - 8 "un mecanismo de readecuación de los hechos ilícitos denunciados por el fiscal y procesados judicialmente, con la observancia de determinados requisitos. Constituye así un principio de mínimo contenido axiológico y máximo carácter técnico autorregulador; cuya comprensión e irradiación abarca el ámbito penal y procesal penal".

Ulteriormente, mediante Decreto Legislativo $\mathrm{N}^{\circ}$ 959, promulgado el 17 de agosto de 2004, se incorpora al Código de Procedimientos Penales, el artículo $285^{\circ}$-A por el cual se permitía modificar la calificación penal, siendo que luego la Corte Suprema de Justicia de la República, mediante Acuerdo Plenario $\mathrm{N}^{\circ}$ 4-2007/CJ-116 publicado en el diario oficial "El Peruano"9, consolidó su posición sobre este tema puntual y analizando el citado principio de congruencia procesal, estimó en primer lugar, que éste se establece entre la acusación oral -por constituir el verdadero instrumento procesal de la acusación - y la sentencia, la cual debe contener la respectiva calificación jurídica, destacando que la norma referida permite degradar; esto es, incorporar 
circunstancias atenuantes, más no sobrepasar (introducir circunstancias nuevas que agraven la responsabilidad, el hecho ni las circunstancias jurídicamente relevantes fijadas en la acusación), dado que sobre este eje se desarrollan los principios acusatorio y de contradicción. Empero, aquel Acuerdo Plenario admite que estas nuevas circunstancias pueden ser apreciadas para sobrepasar la responsabilidad -sin que ello importe una alteración de hechos esenciales de la acusación- planteándose de oficio y en forma previa, la "tesis de desvinculación" mediante la cual se debatirán tales circunstancias modificativas de la responsabilidad que no fueron inicialmente comprendidas en la acusación originaria, aunque también admite prescindencia de esta tesis, cuando hubiere mediado manifiesto error de la opción jurídica correcta.

La Corte Interamericana de Derechos Humanos, en el caso Fermín Ramírez versus Guatemala, trató el principio de correlación acusación - sentencia y el cambio de calificación jurídica bajo la aplicación del ya mentado principio de iura novit curia.

En el hecho de análisis, se acusó a Ramírez por violación calificada (violación seguida de muerte culposa), pero luego el Tribunal estimó que podría tratarse de una calificación jurídica distinta, mas no indicó cual y obviando su expresa normatividad que le imponía tomar nueva declaración al imputado, suspender el debate y permitirle ofrecer nuevas pruebas, advirtiéndole esta nueva postura del Colegiado, permitió se le acusara por asesinato con ensañamiento y con impulso brutal y se le solicitara pena de muerte.

Al final del proceso, en mérito a los hechos probados en juicio, el Tribunal condenó a Ramírez por el citado delito imponiéndole la pena de muerte, luego de desestimarse la apelación formulada en su contra.

Elevada la petición a la Corte Interamericana de Derechos Humanos, la Comisión en ejercicio de sus facultades ya reformadas ${ }^{10}$ reparó que el Ministerio Público no formuló acusación alternativa como así lo facultaba su Código Procesal Penal ${ }^{11}$ (vemos aquí que esta figura procesal ya era aplicada en Guatemala desde 1997); que el fallo se sustentó en hechos no comprendidos en la acusación y que se desconoció el principio de congruencia, "sorprendiéndose" a Ramírez con tal decisión jurisdiccional circunstancia justamente apreciada en el Acuerdo Plenario No 4-2007/CJ-116 de la Corte Suprema de Justicia de la República ${ }^{12}$ al ser violatorio de los derechos a ser informado de la imputación, como de contar con los medios y el tiempo necesarios para preparar su defensa. 
La Corte Interamericana de Derechos Humanos comenzó por definir el principio de congruencia en términos no tradicionales:

"La descripción material de la conducta imputada contiene los datos fácticos recogidos en la acusación, que constituyen la referencia indispensable para el ejercicio de la defensa del imputado y la consecuente consideración del juzgador en la sentencia. De ahí que el imputado tenga derecho a conocer, a través de una descripción clara, detallada y precisa, los hechos que se le imputan. La calificación jurídica de éstos puede ser modificada durante el proceso por el órgano acusador o por el juzgador, sin que ello atente contra el derecho de defensa, cuando se mantengan sin variación los hechos mismos y se observen las garantías procesales previstas en la ley para llevar a cabo la nueva calificación. El llamado principio de coherencia o de correlación entre acusación y sentencia implica que la sentencia puede versar únicamente sobre hechos o circunstancias contemplados en la acusación".

Finalmente concluyó que la República de Guatemala había violado los artículos $8^{\circ}$.2.b y $8^{\circ}$.2.c de la Convención Americana.

Horvitz Lennon, M. I. Derecho Procesal Penal Chileno. Tomo II. Santiago: Editorial Jurídica de Chile, 2002. Pág. 41

2 Cueva Vaccaro, C. Las convenciones probatorias. Trabajo monográfico presentado en la Maestría con mención en Derecho Penal de la Pontificia Universidad Católica del Perú.

3 Jauchen, E. M. Tratado de la prueba en materia penal. Buenos Aires: Rubinzal-Culzoni Editores, Pág. 20.

4 Miranda Estrampes, M. Profesor del Área Penal de la Escuela Judicial (Barcelona) dependiente del Consejo General del Poder Judicial. II Congreso Nacional de Derecho Penal y Criminología. Ponencias Internacionales.

5 Clariá Olmedo, J. A. Principio de congruencia en el proceso penal. En: XI Congreso Nacional de Derecho Procesal, La Plata, 1981. Tomo I. Pág. 363 (citado por Vázquez Rossi, Jorge E. Derecho Procesal Penal. Tomo II. Santa Fe: Rubinzal-Culzoni Editores, 2004. Pág. 456).

6 Cf. Vélez Mariconde, A. Derecho Procesal Penal. Tomo II. Córdova: Lerner Editorial, 1986. Pág. 228.

7 Creus, C. Derecho Procesal Penal. Buenos Aires: Editorial Astrea, 1996. Pág. 117.

8 Monografía Luis Alfredo Alarcón Flores. Monografías.com

9 Pleno Jurisdiccional de las Salas Penales Permanente y Transitorias de la Corte Suprema de Justicia - Lima 16 noviembre de 2007 .

10 Una de las reformas más relevantes en el procedimiento contencioso ante la Corte Interamericana de Derechos Humanos introducidas por el nuevo Reglamento consiste en que, una vez presentada la Demanda de la Comisión, la víctima o sus representantes, son notificados para que decidan si intervendrán con su propia representación, para interponer su demanda, ofrecer prueba y formular solicitudes como la Comisión (Artículo 23․, Reglamento de la Corte Interamericana). 
Gino M. Valdivia Sorrentino

La acusación fiscal y la audiencia preliminar

11 "Artículo 333․- Acusación alternativa: El Ministerio Público, para el caso de que en el debate no resultaren demostrados todos o alguno de los hechos que fundan su calificación jurídica principal, podrá indicar alternativamente las circunstancias de hecho que permitan encuadrar el comportamiento del imputado en una figura delictiva distinta".

12 Considerando 12. -segundo párrafo- (Es sabido que uno de los contenidos de la garantía de defensa procesal, junto con el conocimiento de los materiales de hecho afirmados por la parte contraria, es que los elementos de derecho que puedan servir para conformar la decisión judicial -aducidos por las partes o que pueden proceder de la aplicación del principio iura novit curia- han de permitir a las partes procesales la posibilidad de aducir en torno a los mismos, de suerte que desde una perspectiva negativa están prohibidos los fallos sorpresivos." 